\title{
The influence of congenital heart disease on survival of infants with oesophageal atresia
}

\author{
H Leonard, A M Barrett, J E S Scott, C Wren
}

\begin{abstract}
Objective-To examine the prevalence of congenital heart disease in babies with oesophageal atresia and its influence on outcome.

Design-Retrospective analysis.

Setting-The resident population of one health region.

Results-A total of 153 babies with oesophageal atresia were identified from 509975 live births (0.30 per 1000); 26 (17\%) had cardiac defects. Survival of babies with normal hearts was $97 \%, 97 \%$, and $\mathbf{9 5 \%}$ at one week, one month, and one year. Survival of babies with congenital heart disease was $85 \%, 85 \%$, and $67 \%$ at one week, one month, and one year, but only one of ten deaths was the result of the congenital heart disease. The remaining deaths were due to other congenital malformations, respiratory disease, or chromosome abnormalities.

Conclusions-There is a high prevalence of congenital heart disease in babies with oesophageal atresia. Congenital heart disease is associated with a higher mortality in oesophageal atresia but it is not the cause of it.
\end{abstract}

(Arch Dis Child Fetal Neonatal Ed 2001;85:F204-F206)

Keywords: heart disease; oesophageal atresia; congenital anomalies; mortality

Congenital heart disease is the most common congenital malformation associated with oesophageal atresia. ${ }^{1-3}$ Previous reports have indicated a higher mortality for babies with oesophageal atresia if there is associated heart disease. ${ }^{4-7}$ However, these institution based series are written from a surgical perspective and could be biased because of early deaths before referral to the centre or because institutions with an interest in the diagnosis may attract a disproportionate amount of more complicated referrals from other centres. Many of the cardiac abnormalities reported are minor and would be expected to have a low mortality, ${ }^{8-10}$ so the pronounced influence of congenital heart disease on survival is surprising.

This retrospective population based study was performed to analyse the prevalence and type of cardiac anomalies associated with oesophageal atresia and their effect on outcome.

\section{Methods}

PATIENT IDENTIFICATION

The former Northern Health Region of England is geographically well defined and has a population of about three million. There is only one tertiary referral centre for paediatric cardiology and one for major paediatric surgery. With the exception of the health district of South Cumbria, which was excluded from this study, there is no cross border referral of infants with suspected heart or gastrointestinal malformation.

Patients with oesophageal atresia were identified from the Northern Regional Congenital Abnormality Survey, a register of all babies with congenital malformations born in the region. Its methodology has been described elsewhere and it includes all liveborn cases, even when diagnosis was made after death. ${ }^{11}$ Babies with cardiovascular malformations were identified from the paediatric cardiology database and Northern Regional Congenital Abnormality Survey. Hospital records and operating theatre books were used to cross check data. The total live birth rate for the region was obtained from the Office for National Statistics.

Patients included are those live born with oesophageal atresia and/or cardiovascular malformation to mothers resident in the Northern Health Region between 1985 and 1998.

CLASSIFICATION OF CARDIAC DEFECTS

In common with most studies of congenital heart disease, cardiovascular malformations were defined as "a gross structural abnormality of the heart or intrathoracic vessels that is actually or potentially of functional importance" ${ }^{12}$ We did not include isolated dextrocardia, right aortic arch, mild physiological pulmonary artery branch stenosis, isolated arrhythmia, cardiac tumours, bicuspid aortic valve with no stenosis, mitral valve prolapse with no regurgitation, cardiomyopathy, or patent ductus arteriosus that closed spontaneously in the first three months. Cardiac defects were classified as complex, significant, or minor. This methodology has been described elsewhere, ${ }^{13}$ but, in brief, malformations are described as complex if they are characterised by atresia or hypoplasia of a valve or chamber, significant if four chambers and four valves were present but treatment was or would be necessary, and minor if no intervention was necessary. Atrial septal defects and patent ductus arteriosus requiring surgery were classified as significant.

\section{STATISTICAL ANALYSIS}

Standard relative risk method was used to assess prevalence of congenital heart disease in the background and population with oesophageal atresia. ${ }^{14}$ 
Table 1 Cardiac abnormalities in oesophageal atresia

\begin{tabular}{ll}
\hline Complex & 4 \\
Tricuspid atresia & 1 \\
Truncus arteriosus & 1 \\
Complete atrioventricular septal defect & 2 \\
& 15 \\
Significant & 1 \\
Transposition of the great arteries & 2 \\
Tetralogy of Fallot & 8 \\
Large ventricular septal defect & 2 \\
Atrial septal defect & 2 \\
Patent ductus arteriosus and small ventricular & \\
septal defect & 7 \\
Minor & 7 \\
Small ventricular septal defect & \\
\hline
\end{tabular}

\section{Results}

A total of 153 liveborn babies with oesophageal atresia were identified among 509975 live births, giving a prevalence of oesophageal atresia of 0.30 per 1000 live births. Fourteen babies had atresia of the small or large intestine as well. Twenty six of 153 (170 per 1000) babies had cardiac defects. There were 3764 babies with congenital heart disease $(7.38$ per 1000) without oesophageal atresia in the same population. The relative risk for congenital heart disease in babies with oesophageal atresia compared with the background population was 23 (95\% confidence interval (CI) 15.2 to 34.9).

During the period of the study, there were eight fetuses with oesophageal atresia and 104 fetuses with congenital heart disease whose pregnancies were terminated. All eight with oesophageal atresia had associated malformations: two had chromosomal abnormalities and three had congenital heart disease as well as other congenital malformations. Of the 104 fetuses with congenital heart disease, 20 had other malformations and 28 had a chromosomal abnormality. Fetuses where pregnancies where terminated were not included in further study.

TYPE OF CONGENITAL HEART DISEASE

Table 1 lists the 26 cardiac diagnoses in patients with oesophageal atresia. Four (15\%) had complex heart disease, $15(58 \%)$ significant heart disease, and seven (27\%) minor heart disease.

The prevalence of complex, significant, and minor heart defects in the denominator population of 509822 live births was 482, 1568, and 1714 respectively (3764 in total). In the 153 babies with oesophageal atresia, the relative risk of complex congenital heart disease was
32.1 (95\% CI 12.2 to 84.6 ), the relative risk of significant congenital heart disease was 34.2 ( $95 \%$ CI 21.1 to 55.3), and the relative risk of minor congenital heart disease was 15.5 (95\% CI 7.5 to 31.9 ) compared with the denominator population.

CHROMOSOMAL ABNORMALITIES

Four patients with oesophageal atresia and congenital heart disease had trisomy (three trisomy 21 and one trisomy 18), and one had Fanconi's anaemia. No patient with oesophageal atresia and a normal heart had a chromosomal abnormality.

OUTCOME FOR BABIES WITH OESOPHAGEAL

ATRESIA AND NORMAL HEARTS

Two babies died on day 1, before operation or referral to the surgical unit: one from tracheal agenesis and one from bilateral renal agenesis.

Survival of babies with normal hearts was $97 \%, 97 \%$, and $95 \%$ at one week, one month, and one year respectively. There were five deaths beyond a year; three from large aspiration and respiratory failure, one after sudden respiratory difficulties at home, and information was not available on the fifth.

OUTCOME FOR BABIES WITH OESOPHAGEAL ATRESIA AND CONGENITAL HEART DISEASE Overall survival of babies with congenital heart disease at one week, one month, and one year was and $85 \%, 85 \%$, and $65 \%$. For those with significant or complex defects, survival was $79 \%, 79 \%$, and $58 \%$. There was one death beyond a year in a child undergoing repair of tetralogy of Fallot.

Table 2 gives information on cause of death for the ten patients with cardiac defects who died. Only one death was directly related to a cardiac problem.

\section{Discussion}

This is the largest study of its kind with a denominator population of over 500000 live births and provides a precise birth prevalence of oesophageal atresia and associated cardiac defects within a population. Congenital heart disease is 23 times more common in association with oesophageal atresia. The spectrum of cardiac malformations in oesophageal atresia is not significantly different from that seen in babies without oesophageal atresia.

We believe ascertainment of oesophageal atresia is complete because it does not cause diagnostic ambiguity and cannot remain "covert". We have used several sources to cross

Table 2 Cause of death in babies with oesophageal atresia and cardiovascular malformations

\begin{tabular}{lllll}
\hline & Atresia & Cardiac defect & $\begin{array}{c}\text { Age at death } \\
\text { (days) }\end{array}$ & Cause of death \\
\hline 1 & OA & Truncus arteriosus & 1 & Bilateral renal dysgenesis/lung hypoplasia \\
2 & OA & CAVSD & 1 & Trisomy 21 (no active treatment) \\
3 & OA+AA & Large VSD & 1 & Bilateral renal agenesis/lung hypoplasia \\
4 & OA & Large VSD & 3 & Trisomy 18 (no active treatment) \\
5 & OA & Small VSD & 69 & Bronchomalacia/respiratory obstruction \\
6 & OA & Tetralogy of Fallot & 236 & Oesophageal haemorrhage \\
7 & OA+DA+AA & Large VSD (repaired age 5 months) & 287 & Large aspiration \\
8 & OA & Tricuspid atresia & 313 & No information available \\
9 & OA & Large VSD (repaired age 1 month) & 352 & Chronic lung disease/respiratory infection \\
10 & OA & Tetralogy of Fallot & 455 & Cardiac surgery \\
\hline
\end{tabular}

CAVSD, Complete atrioventricular septal defect; VSD, ventricular septal defect; OA, oesophageal atresia; DA, duodenal atresia; $\mathrm{AA}$, anorectal atresia. 
check data. The birth prevalence of oesophageal atresia in our population is similar to that in previous studies. ${ }^{10}$ However, the prevalence of cardiac defects in our patients with oesophageal atresia is towards the lower end of the range quoted in other studies $(13.2-39 \%))^{2}{ }^{15}$ This is probably because other studies have included right aortic arch and dextrocardia, which may have surgical significance, but do not qualify as structural congenital heart disease and have no influence on mortality.

Survival in children with oesophageal atresia and normal hearts is excellent (particularly as we have included deaths before presentation to the referral centre). Other long term studies have noted appreciable improvements in survival in recent years. ${ }^{316}$ This reflects advances in surgery and neonatal care of previously high risk groups such as low birth weight infants and infants with cardiac problems. ${ }^{17}{ }^{18}$ Survival in the group with congenital heart disease is poorer, but nine of ten deaths in this group were not related to the cardiac problem. These babies were much more likely to have an underlying syndrome or additional anomaly (such as renal dysgenesis) which had a direct effect on outcome. Four of the ten deaths were in babies who underwent no active treatment because of trisomy or renal agenesis.

The high prevalence of congenital heart disease is an indication for screening. Antenatal detection of oesophageal atresia should prompt referral for detailed fetal cardiac scanning. If there is no antenatal diagnosis, the timing of postnatal screening for cardiac disease (whether it should be performed urgently before surgery) is debatable and there are different recommendations about this..$^{12} 20 \mathrm{We}$ found no early deaths resulting from congenital heart disease and only one cardiac malformation that required early intervention (transposition of the great arteries). Therefore, if the baby is acyanotic with no signs of cardiac disease, we agree with Spitz et $a l^{19}$ that a preoperative cardiac consultation is not mandatory and can be deferred until after oesophageal repair.

Antenatal or postnatal detection of congenital heart disease in association with oesophageal atresia is an indication for genetic testing and careful screening for other fetal abnormalities. If no other abnormalities are detected, congenital heart disease is unlikely to have a significant effect on mortality in babies with oesophageal atresia.

We are grateful to Marjorie Renwick, at the Regional Maternity Survey Office, and Kati Whiteoak, who maintains the paediatric Survey Office, and Kati Whiteoak, who maintains the paediatric are indebted to the Children's Heart Unit Fund for financial are indebted to the Children's Heart Unit Fund
support of the paediatric cardiology database.

1 Chittmittrapap S, Spitz L, Kiely EM, et al. Oesophageal

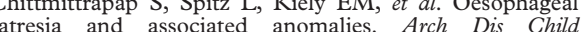
atresia and $1989 ; 64: 364-8$.

2 Myers NA, Beasley SW, Auldist AW. Oesophageal atresia and associated anomalies: a plea for uniform documentation. Pediatr Surg Int 1992;7:97-100.

3 Okada $\mathrm{A}$, Usui $\mathrm{N}$, Inoue $\mathrm{M}$, et al. Esophageal atresia in Osaka: a review of 39 years experience. $\mathcal{F}$ Pediatr Surg 1997;32:1570-4.

4 Mellins RB, Blumenthal S. Cardiovascular anomalies and esophageal atresia. American fournal of Diseases in Children 1964;107:96-100.

5 Choudry SR, Ashcraft KW, Sharp RJ, et al. Survival of patients with esophageal atresia: influence of birth weight, cardiac anomaly and late respiratory complications. F Pediatr Surg 1999;34:70-4.

6 Holder TM, Ashcraft KW, Sharp RJ, et al. Care of infants with esophageal atresia, tracheoesophageal fistula and with esophageal atresia, tracheoesophageal fistula and 1987;94:828-35.

7 Beasley SW, Myers NA. Trends in mortality in oesophageal atresia. Pediatr Surg Int 1992;7:86-9.

8 Kimble RM, Harding J, Kolbe A. Additional congenital anomalies in babies with gut atresia or stenosis: when to investigate, and which investigation. Pediatr Surg Int 1996;12:565-70.

9 Poenaru D, Laberge J-M, Neilson IR, et al. A new prognostic classification for esophageal atresia. Surgery 1993;113:426-32.

10 Greenwood RD, Rosenthal A. Cardiovascular malformations associated with tracheoesophageal fistula and estions associated with tracheoesophageal
ophageal atresia. Pediatrics 1976;57:87-91

11 Northern Regional Survey Screening Group. Fetal abnormality, an audit of its recognition and management. Arch mality, an audit of its recognition and managem

12 Mitchell SC, Korones SB, Berendes HW. Congenital heart disease in 56,109 births. Circulation 1971;43:323-32.

13 Wren C, Richmond S, Donaldson L. Temporal variability in birth prevalence of cardiovascular malformations. Heart 2000;83:414-19.

14 Bland JM, Altman DG. The odds ratio. BMF 2000;320:1468

15 Tulloh RMR, Tansey SP, Parashar K, et al. Echocardiographic screening in neonates undergoing surgery for selected gastrointestinal malformations. Arch Dis Child Fetal Neonatal Ed 1994;70:F206-8.

16 Ein SH, Shandling B. Pure esophageal atresia: a 50 year review. F Pediatr Surg 1994;29:1208-11.

17 Waterston DJ, Bonham Carter RE, Aberdeen E. Oesophageal atresia: tracheo-oesophageal fistula. A study of geal atresia: tracheo-oesophageal fistula.
survival in 218 infants. Lancet 1962:819-22.

18 Myers NA. Oesophageal atresia. Pediatr Surg Int 1992;7:835

19 Spitz L, Kiely EM, Morecroft JA, et al. Oesophageal atresia: at risk groups for the 1990s. $\mathcal{F}$ Pediatr Surg 1994;29:723-5.

20 Mee RB, Beasley SW, Auldist AW, et al. Influence of congenital heart disease on management of oesophageal atresia. Pediatr Surg Int 1992;7:90-3. 